\title{
HIGH POWER SWITCH FOR THE SMTF MODULATOR*
}

\author{
M. N. Nguyen, R. L. Cassel \\ Stanford Linear Accelerator Center, 2575 Sand Hill Rd., Menlo Park, CA 94025, U.S.A.
}

\section{Abstract}

A compact, water cooled, high power switch for the Superconducting Module Test Facility (SMTF) long-pulse klystron modulator has been constructed and implemented at the Fermi National Accelerator Laboratory (FNAL). This solid-state switch is composed of six series devices, each having a rating of $4.5 \mathrm{kV}$ and 2000 Adc. Latest generation, press-pack IGBT modules are utilized to reduce the physical size and complexity of the switch assembly. The new switch and its associated controller provide a high degree of redundancy and fail-safe operation, which meets the modulator requirements. This paper describes the general switch assembly, IGBT protection and control schemes, and test results.

\section{INTRODUCTION}

FNAL is building two new modulators to power developmental superconducting RF systems. These modulators are the third version of the "bouncer" design [1] that is being used at DESY in the TESLA test facility and is considered the "baseline design" for the ILC klystron modulator. In this design, a $10 \mathrm{kV}$ capacitor bank is discharged through a direct switch onto a step-up transformer to generate output pulses. In series with the transformer primary is the "bouncer" tank circuit whose voltage is used to compensate for the capacitor bank droop and to flatten the primary pulse. The SMTF modulator and switch requirements are as follows:

- Modulator Voltage

$120 \mathrm{kV}$

- Modulator Current

$140 \mathrm{~A}$

- Pulse Width

- Pulse Repetition Rate
- Switch Nominal Voltage

$10 \mathrm{kV}$

- Switch Nominal Current

$1680 \mathrm{~A}$

- Switch Max. Voltage at Load Fault

$14.2 \mathrm{kV}$

- Switch Max. Current

$1850 \mathrm{~A}$

- Redundancy: the switch must accommodate two independent control signals and be constructed such that no single component failure can prevent it from being turned-off.

The switching elements have changed with the advancement of technology on each new version of the bouncer modulator. From GTOs, to flat-pack IGBTs, to IGCTs for the TESLA, latest high voltage and high current pressure-contact IGBT modules [2] are utilized for the new SMTF modulator. The advantages of IGBT are well known. Additionally, the press-pack configuration provides some distinct benefits that are particularly well suited for high peak power, long pulse applications: inherently low inductances, easy series stacking and an excellent power cycling capability. Without wire bonding and solder to break, these press-pack IGBTs will significantly improve the reliability of the new switch.

\section{GENERAL DESCRIPTION}

A block diagram of the complete switch is shown in Fig. 1. It consists of three main components: IGBTs with gate driver boards and snubber assemblies, the isolated power source, and the control chassis. Westcode Semiconductor $85 \mathrm{~mm}$, press-pack IGBT was chosen as the switching element. This device (without internal antiparallel diodes) is rated for $4500 \mathrm{~V}$ and $2000 \mathrm{~A}$ continuous duty cycles. It is the largest commercially available IGBT at this time.

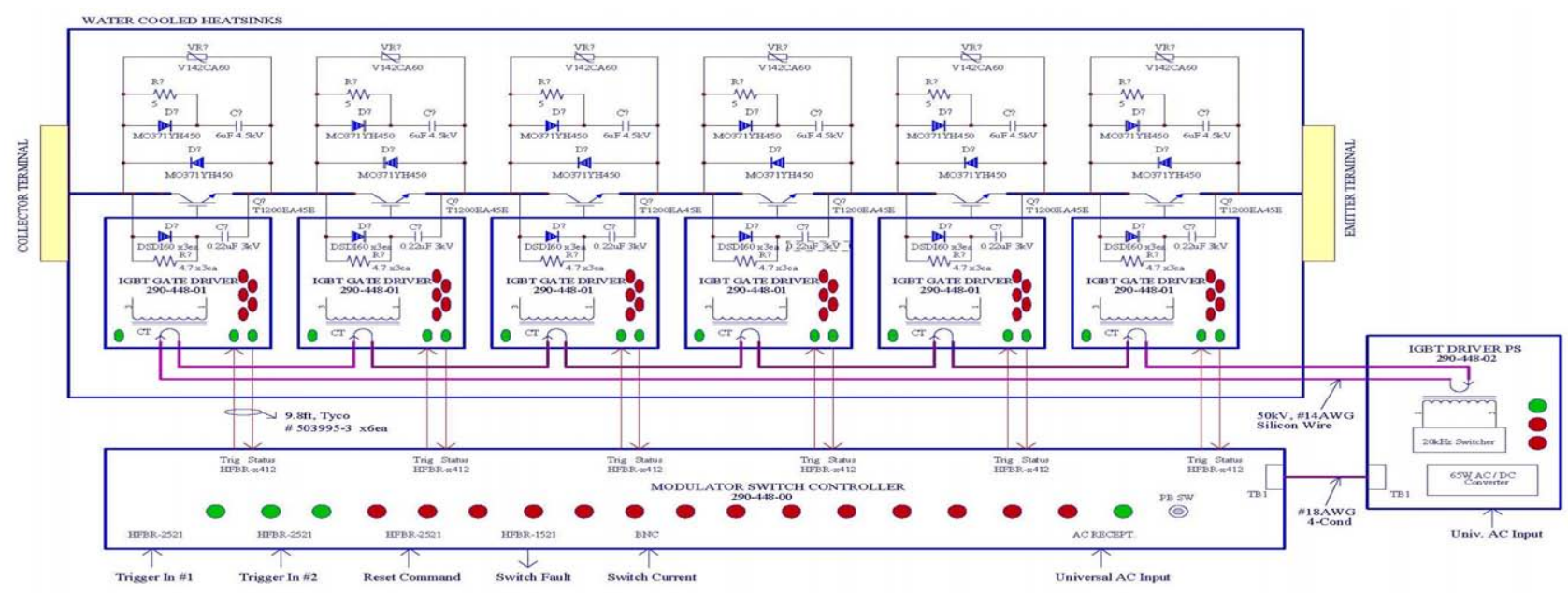

Figure 1: Switch block diagram. 
Six of these devices, stacked in series, form the 27 $\mathrm{kV}$ switch. Built-in redundancies such as extra blocking voltage margin, separating high current components and dual-command on/off controls assure high availability and reliability. In addition, power for the IGBT gate drivers and fail-safe logic are doubly isolated by corona-free switch-mode transformers. Fiber-optic cables link the switch assembly with the control chassis. The overall switch dimension is approximately 15 " L x 12 " W x 24 " $\mathrm{H}$, and it weights about $75 \mathrm{lbs}$.

\section{MECHANICAL ASSEMBLY}

Fig. 2 shows the construction and components of one of the six cells/IGBTs. The basic block of each cell assembly is a 12-inch, liquid-cooled cold plate from Aavid Thermalloy. It is machined to accommodate the IGBT module, the anti-parallel diode, the MOV and the R-C-D snubber network - this rather large snubber is necessary to meet the required turned-off voltage during klystron arcs. Belleville high-carbon steel disc springs in various sizes and thickness are placed underneath each component, except the IGBT. These springs, when compressed, would provide appropriate pressure for each part.

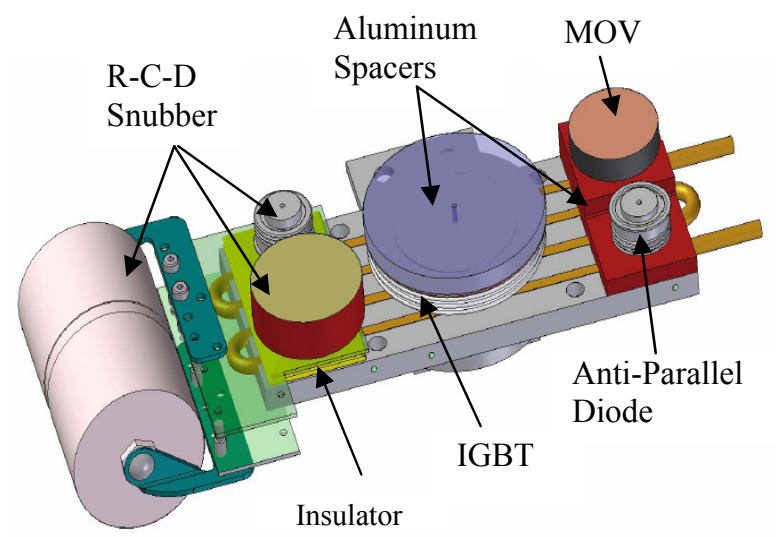

Figure 2: Single cell construction.

The cells are then stacked up via four mounting holes on the cold plate through $1 / 2$ inch G-10 rods. Two steel end plates, with multiple larger Belleville springs in between, compress the cells/IGBTs. Typical IGBT mounting force of $20-25 \mathrm{kN}$ is determined by checking and measuring the deflection of these springs. The complete structure is electrically isolated from ground by two 6-inch Glastic standoff insulators. An assembled switch is shown in Fig. 3.

\section{ELECTRICAL CHARACTERISTICS}

\section{Protection}

To ensure that no single component failure can short the entire switch, each IGBT is independently protected against over voltage and over current.

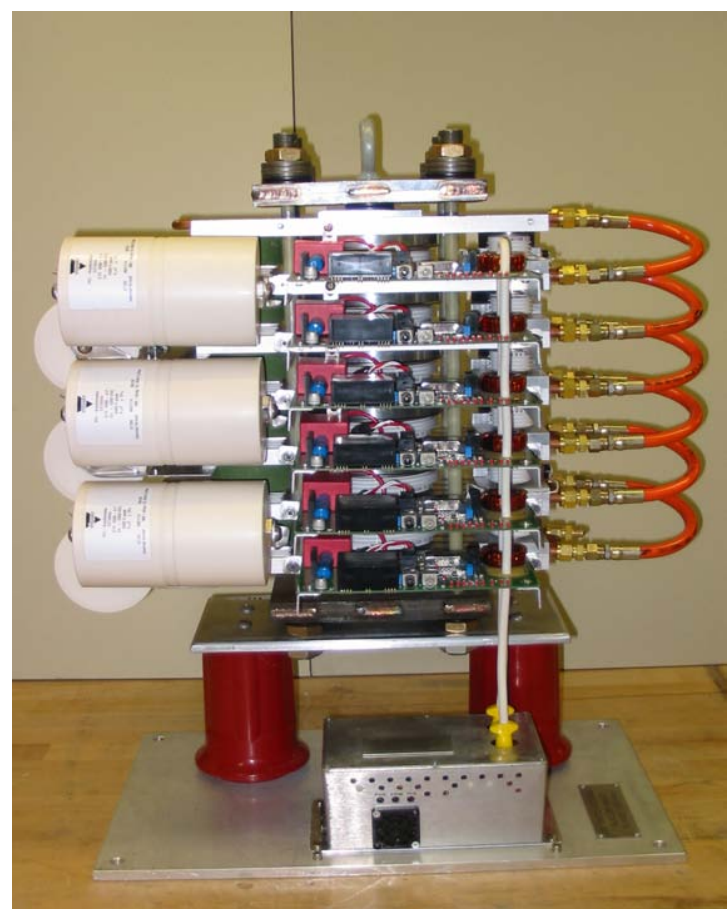

Figure 3: Switch photograph.

Reverse current is bypassed through anti-parallel, soft recovery diodes. Resistive dividers provide static voltage sharing between cells. During turn-off, peak voltage and dynamic voltage sharing are by means of two R-C-D snubber networks. The large, oil-filled GTO snubber capacitors rated $4.5 \mathrm{kV}, 6.0 \mu \mathrm{F}$ each, are installed for two reasons: to limit the peak switch voltage to less than $14.2 \mathrm{kV}$ at the peak arc current of $1850 \mathrm{~A}$, and to improve the switch reliability. The much smaller, self-healing type, plastic film capacitors failed when connected in parallel. In addition: $60 \mathrm{~mm}$ disc MOV, capable of clamping $2000 \mathrm{~A}$ at $4 \mathrm{kV}$, is used to limit the cell voltage. IGBT over-current is controlled by driving the IGBT Gate-Emitter (GE) at slightly less than $15 \mathrm{~V}$ and by terminating the trigger pulse when high Collector-Emitter (CE) de-saturation voltage is detected.

\section{Control}

A control board that provides bipolar $15 \mathrm{~V}, 15 \mathrm{~A}$ IGBT gate drives and monitoring circuits is mounted on each cell. Continuous monitoring is provided for cold-plate temperatures and common IGBT faults such as $\mathrm{CE}$ open, $\mathrm{CE}$ shorted, GE under-voltage; triggers are inhibited upon any detected faults Also, on board is a small R-C-D snubber to suppress fast transients generated by stray inductance in the large snubber. In order to maintain control of the switch during AC power failures or arc events, the gate drive power is retained for more than $100 \mathrm{mS}$ after the power source is removed. This is sufficient time to open the switch and to allow the main modulator capacitor bank to discharge, before the control power is interrupted. 
Power to each gate control board is delivered through two series isolation transformers driven by a $20 \mathrm{kHz}$ switcher. The common winding between these two transformers is fully isolated with $50 \mathrm{kV}$ silicon wire and is monitored for voltage breaches; switch triggering would then be inhibited should an event occur. The low voltage, high current switcher can supply up to $60 \mathrm{~W}$ of power, and is regulated against shorted circuits on the gate control boards. Power supply under-voltages and faults in the switcher would also stop all triggers to the IGBTs.

To meet the required redundancy, the switch control chassis has two separate circuits to accommodate two fiber-optic on/off trigger inputs. The triggers must be simultaneously presented to turn on the switch. Delays of more than $1 \mu \mathrm{S}$ between one of the inputs will inhibit the output. The controller receives fail-safe status signals from each IGBT in the switch array and either inhibits or allows the IGBTs to be triggered accordingly. Switch currents are compared with an adjustable reference voltage to detect an over-current situation and gate off the trigger. Several LEDs on the front panel indicate the status of the switch and each of IGBT conditions.

\section{TEST RESULTS}

Functional tests of the switch were carried out using the test circuit shown in Fig. 4. Major components are: a $200 \mu \mathrm{F}$ energy storage capacitor, a $5.7 \mathrm{ohms}$ resistive load, the IGBT switch array and a $50 \mu \mathrm{H}$ inductor to limit the current rate of rise as specified by the SMTF modulator. The trigger pulse width was limited to 100 $\mu \mathrm{S}$ to minimize droop on the energy storage capacitor. Fig. 5 shows waveforms of the switch differential voltage and current during normal operation.

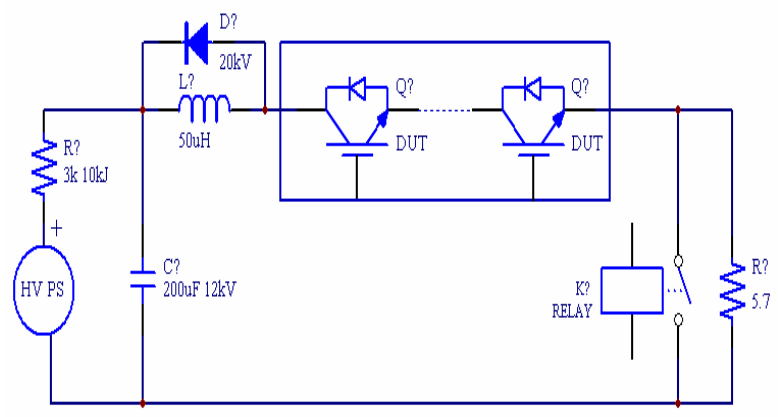

Figure 4: Test circuit.

Short circuit tests were implemented using a drop switch placed across the resistor load. Switch current was limited to about 1900 A to verify turned-off peak voltages and the voltage sharing between cells. Resultant waveforms are shown in Fig. 6. Thermal testing, using 1 GPM water flow rate and 50 PSI pressure drop, raised each IGBT temperature just $1^{\circ} \mathrm{C}$ for $120 \mathrm{~W}$ of average power losses.

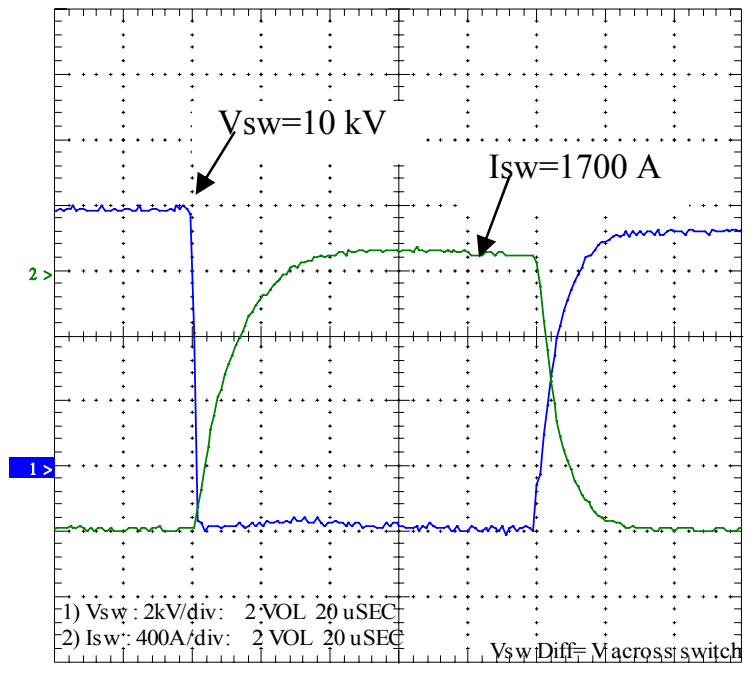

Figure 5: Normal test waveforms.

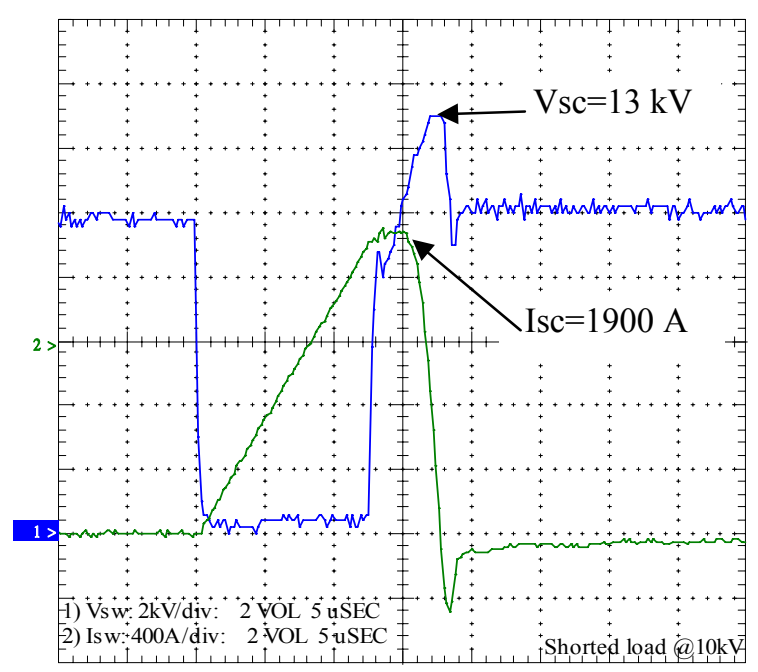

Figure 6: Short-circuited test waveforms.

\section{CONCLUSION}

In collaboration with FNAL, SLAC has successfully designed, built and tested two compact, high power switches for the SMTF modulator. One of these switches has been installed and is currently in operation.

\section{ACKNOWLEDGMENTS}

The authors would like to thank D. Anderson, W. Gorecki and J. Olszewski for their superb mechanical and drafting skills, as well as H. Pfeffer and C. Jensen of Fermi Lab for valuable discussions.

\section{REFERENCES}

[1] H. Pfeffer, et. al., "A Long Pulse Modulator For Reduced Size And Cost", EPAC'94, London.

[2] F. Wakeman, et. al., "Electromechanical Characteristics Of A Bondless Pressure Contact IGBT", Westcode Semiconductors Ltd. 